Aletria, Belo Horizonte, v. 29, n. 1, p. 179-195, 2019

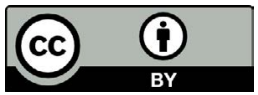

\title{
"Escrever é sangrar": reflexões sobre ancestralidade, racismo e dor em Olhos d'água de Conceição Evaristo ${ }^{1}$
}

\section{"Writing is Bleeding": Reflections on Ancestry, Racism and Pain in Olhos d'água by Conceição Evaristo}

\author{
Natalino da Silva de Oliveira \\ Instituto Federal do Sudeste de Minas Gerais, Muriaé, Minas Gerais / Brasil \\ natalinoletras@gmail.com
}

Resumo: O objetivo deste artigo é analisar o conto Olhos d'água, de Conceição Evaristo, abordando questões de identidade, ancestralidade e racismo e suas relações com a situação do negro no Brasil. Além disso, visa demonstrar como se dá na narrativa citada a reflexão sobre a nacionalidade incompleta do negro brasileiro, partindo das noções de história e ideologia do progresso em Benjamin, de branqueamento e racismo em Fanon e de Estado de exceção em Agamben. Por meio da abordagem conjunta entre textos teóricos e texto literário, almeja-se seguir os rastros de uma formação de identidade, ainda que reconstruída e fragmentada. Afinal, seria possível construir a memória a partir de cacos, de escombros e a partir dela fortalecer valores identitários? Palavras-chave: negro; memória; identidade; nacionalidade; Conceição Evaristo, Olhos d'água.

Abstract: This article's objective is to analyze the short story Olhos d'água, by Conceição Evaristo, addressing issues of identity, ancestry and racism and their relations with the situation of black people in Brazil. In addition, it aims to demonstrate how the reflection on the incomplete nationality of the Brazilian negro develops itself, starting from the notions of history and ideology of progress in Benjamin, of laundering and

${ }^{1}$ Este artigo foi financiado com recursos da FAPEMIG / Edital № 460/2017 Participação Individual em Evento no País e com recursos de Bolsa Pesquisador da PROPESQINOV - IF SUDESTE MG edital 2018. 
racism in Fanon and of State of Exception in Agamben. Through a joint approach between theoretical texts and literary text, it sought to follow the traces of an identity formation, though rebuilt and fragmented. After all, would it be possible to build memory from shards and debris and then strengthen identity values?

Keywords: black people; memory; identity; nationality; Conceição Evaristo, Olhos d'água.

"Escrever é uma maneira de sangrar". Acrescento e de muito sangrar, muito e muito... ${ }^{2}$

\section{Sobre memória negada}

Quem construiu a Tebas de sete portas? Nos livros estão nomes de reis. Arrastaram eles os blocos de pedra? E a Babilônia várias vezes destruída? Quem a reconstruiu tantas vezes? Em que casas Da Lima dourada moravam os construtores? ${ }^{3}$

A nacionalidade do negro no Brasil (e em todos os países em que o negro foi forçosamente trazido na condição de escravizado) se deu de forma incompleta compreendendo apenas deveres, sem contemplar direitos iguais. Sentir-se brasileiro é para o negro uma condição desequilibrada e que apresenta artificialidades diversas. A identidade afro-brasileira se apresenta, portanto, em trânsito, variando em proporções que se encontram profundamente relacionadas com seu grau de instrução, com sua condição social, com sua interação política e cultural na sociedade. Porém, em todas as proporções há um vazio. Esse vácuo surge da memória ausente, da memória negada, da memória que, fragmentada, resiste a duras penas.

O povo negro é constituído por uma memória criada e ficcionalizada de forma forçada em uma história oficial forjada. As narrativas oficiais oprimem a realidade dos afrodescendentes. Durante muito tempo e até mesmo nos dias de hoje, os negros têm permanecido como objetos da letra, e não como cidadãos letrados; são prisioneiros

\footnotetext{
${ }^{2}$ EVARISTO. Olhos d'água, p. 109.

${ }^{3}$ BRECHT. Poemas, p. 167.
} 
de narrativas escritas por outras pessoas e não são apresentados como protagonistas. $\mathrm{O}$ direito da escrita foi negado aos negros e quando, em raríssimas exceções, aparecem como autores, o questionamento da elite surge. Seria literatura aquilo que os negros produzem? Tal como ocorreu recentemente com Carolina Maria de Jesus em lamentável episódio na Academia Carioca de Letras. ${ }^{4}$

Ao analisar a situação do negro no Brasil é possível reconhecer que ele se encontra em diferentes modos no entre-lugar: entre fé católica/ cristã (que por muito tempo não o reconheceu enquanto pessoa, ser humano) e as religiões de origem africana (que durante muito tempo foram proibidas e que até hoje são perseguidas), entre a oralidade e a escrita, entre assumir seus costumes culturais sofrendo as perseguições da esfera social ou aceitar o branqueamento como forma de defesa e sobrevivência. Contudo, ainda que aceite as estratégias forçadas de pertencimento, o negro ainda será considerado um cidadão de segunda classe.

[...] o "pertencimento" e a "identidade" não têm a solidez de uma rocha, não são garantidos para toda a vida, são bastante negociáveis e revogáveis [...] as decisões que o próprio indivíduo toma, os caminhos que percorre, a maneira como age - e a determinação de se manter firme a tudo isso - são fatores cruciais tanto para o "pertencimento" quanto para a "identidade". ${ }^{5}$

Porém, assim como há momentos de luta, existem também momentos de glória em manifestações literárias do negro brasileiro; ainda que, aparentemente, nas histórias dos negros no Brasil esses dois momentos se fundam, pois o tempo para aproveitar e comemorar vitórias se mistura com o tempo de novas batalhas e incansáveis demandas. Destaco neste artigo um desses momentos de fusão entre glória e luta: a contribuição de Conceição Evaristo em capítulo significativo da história das produções literárias do negro no Brasil - aliás, da negra no Brasil.

\footnotetext{
${ }^{4}$ Em um evento da Academia Carioca de Letras em homenagem à escritora, realizado no dia 17 de abril de 2017, o estatuto de obra literária atribuído a Quarto de despejo foi questionado por Ivan Cavalcanti Proença que foi prontamente rebatido pelo posicionamento acertado de Elisa Lucinda.

${ }^{5}$ BAUMAN. Identidade: entrevista a Benedetto Vecchi, p. 17-18. (Grifos do autor)
} 
É necessário reforçar a questão de gênero; afinal, ser negro no Brasil apresenta faces com intensidades de dores diferentes, relacionadas à classe social, ao grau de instrução formal, ao gênero. Sendo assim, há em Evaristo a preocupação em apresentar o negro como protagonista, particularmente em Olhos d'água, conto que problematiza, que toca na ferida, que sensibiliza e que, principalmente, testemunha e aponta os autores das violências sofridas pela comunidade negra que é vítima do racismo que impera no país. Deste modo, o objetivo deste artigo é buscar refletir, na narrativa de Evaristo, as condições em que a memória se apresenta como forma de estruturar uma identidade possível, palpável.

\section{A memória da mulher negra em Conceição Evaristo - três dores, três discriminações}

Ao negro não foi dado o direito à história. Há os que afirmam que a "história é contada pelos vencedores", contudo gostaria de fazer uma adaptação da frase para que esta reflita a realidade: "a história é contada pelos usurpadores e malfeitores" - e no caso específico do povo negro, a história foi contada pelos feitores. Isso não significa, de modo algum, que este povo tenha se calado. Em livros oficiais, a voz presente não é a do negro (protagonista), mas no samba, na capoeira, nos congados, nas artes periféricas e até mesmo na literatura, é possível ouvir o grito genuíno desta subalternizada e expressiva camada popular. Não temos a história oficial, contudo temos o que restou de nossas memórias. Guardados tesouros, contados e entremeados na oralidade, sobrevivem em pequeninos cacos que montamos com muito esforço. Pois memória é também identidade. $\mathrm{O}$ que nos restou da árvore do esquecimento, recolhemos e armazenamos com muito zelo. Desconfiai, portanto, dos monumentos oficiais, pois tal como afirma Benjamin:

Todo aquele que, até hoje, obteve a vitória, marcha junto no cortejo de triunfo que conduz os dominantes de hoje [a marcharem] por cima dos que, hoje, jazem por terra. A presa, como sempre de costume, é conduzida no cortejo triunfante. Chamam-na bens culturais. Eles terão de contar, no materialismo histórico, com um observador distanciado, pois o que ele, com seu olhar, abarca como bens culturais atesta, sem exceção, uma proveniência que ele não pode considerar sem horror. Sua existência não se deve somente 
ao esforço dos grandes gênios, seus criadores, mas, também, à corveia sem nome de seus contemporâneos. Nunca há um documento da cultura que não seja, ao mesmo tempo, um documento da barbárie. E, assim como ele não está livre da barbárie, também não está do processo de sua transmissão, transmissão na qual ele passou de um vencedor a outro. Por isso, o materialismo histórico, na medida do possível, se afasta desta transmissão. Ele considera como sua tarefa escovar a história a contrapelo. ${ }^{6}$

Aos negros não foi dada nem mesmo a possibilidade de assumirem a condição de testemunhas, não foi dado o direito da ampla defesa e do contraditório, quem dirá então, o direito de serem protagonistas de suas próprias histórias. Por isso, por muitas vezes, ocorre um processo de negação por parte do negro de sua própria origem (africana) para forjar forçosamente e artificialmente uma nova realidade (europeia). Durante esse doloroso processo pode ocorrer o fenômeno de branqueamento caracterizado pelo extremismo de negação das raízes. Ser negro, assumirse negro, é um processo de reconciliação consigo mesmo. "EnegreSER" é um vocábulo que gosto de escrever desta forma, que parece equivocada na língua portuguesa denominada "padrão", mas que traz uma gama maior de significados. Pois ser negro é um processo, é construir-se negro. É esta busca em montar o quebra-cabeça, de escrever a partir das "quebradas", das periferias do Brasil que encontramos nas narrativas de Evaristo.

A partir deste momento, já me é impossível manter o texto em terceira pessoa. Já não posso mais seguir mantendo uma pressuposta ilusão de objetividade, se é que alguma vez na vida consegui. Sobretudo ao abordar uma dor que é também minha dor. Então não vou mais usar a terceira pessoa. Pois assim como Césaire: "Falo de milhões de homens em quem deliberadamente inculcaram o medo, o complexo de inferioridade, o tremor, a prostração, o desespero, o servilismo". ${ }^{7}$ Homens e Mulheres que sofrem o cotidiano de humilhação, exploração e ausência total de direitos. A falsa ideia de progresso, portanto, não apaga de minha memória e nem das memórias das personagens de Evaristo a situação de violência direta e indireta que o negro no Brasil vive.

\footnotetext{
${ }^{6}$ BENJAMIN. Magia e técnica, arte e política, p. 156-157.

${ }^{7}$ CÉSAIRE. Discurso sobre o colonialismo apud FANON. Pele negra, máscaras brancas, p. 25.
} 
[...] a temporalidade do passado não se reduz mais ao espaço indiferente de uma anterioridade que precede o presente na linha monótona da cronologia; ao contrário, momentos esquecidos do passado e momentos imprevisíveis do presente, justamente porque são separados, portanto "distantes", se interpelam mutuamente numa imagem mnêmica que cria uma nova intensidade temporal. Em oposição à representação de uma linearidade contínua e ininterrupta do tempo histórico, representação cuja relevância ideológica para a manutenção do existente deve ser realçada, essa concepção disruptiva e intensiva de "atualidade" coloca em questão a narração dominante da história, isto é, também, a compreensão de um passado cujo sentido pode revelar-se outro e autocompreensão de um presente que poderia ser diferente. ${ }^{8}$

A violência contra a história do negro no Brasil também se configura na valorização da ideia de meritocracia. O processo seria a construção do mito de progresso. Como se fosse única e fundamentalmente responsabilidade do sujeito o seu caminho rumo à ocupação de algum espaço na elite brasileira. Em seu livro Pele negra, máscaras brancas, Fanon aborda especificamente a questão do racismo e suas consequências na vida das mulheres negras no capítulo intitulado "A mulher de cor e o branco". Porém, ainda assim, é possível abordar muitas das situações e análises presentes no livro de Fanon para a realidade brasileira. A situação do negro na sociedade brasileira não é muito diferente da situação do negro em outros países. O que se apresenta é quase sempre um verdadeiro cenário de marginalização. "O negro é um homem negro; isto quer dizer que, devido a uma série de aberrações afetivas, ele se estabeleceu no seio de um universo de onde será preciso retirá-lo". ${ }^{9}$ O negro no Brasil e em outras partes do mundo é antes de tudo "um homem negro" e isso encerra toda sua trajetória enquanto ser.

Já dissemos que existem negrófobos. Aliás, não é o ódio ao negro que os motiva. Eles não têm a coragem de odiar, ou não a têm mais. O ódio não é dado, deve ser conquistado a cada instante, tem de ser elevado ao ser em conflito com

\footnotetext{
${ }^{8}$ GAGNEBIN. Documentos da Cultura/Documentos da Barbárie, p. 81.

${ }^{9}$ FANON. Pele negra, máscaras brancas, p. 26.
} 
complexos de culpa mais ou menos conscientes. O ódio pede para existir e aquele que odeia deve manifestar esse ódio através de atos, de um comportamento adequado; em certo sentido, deve tornar-se ódio. ${ }^{10}$

Há no Brasil, o massacre diário de negros nas periferias das grandes cidades. Contudo, há também o reforço do racismo nos espaços mais íntimos, em atos, palavras e olhares. Fato semelhante é descrito por Fanon quando analisa a realidade antilhana: "[...] o negro antilhano será tanto mais branco, isto é, se aproximará mais do homem verdadeiro, na medida em que adotar a língua francesa. [...] existe na possa da linguagem uma extraordinária potência [...]". ${ }^{11}$ Portanto, observa-se que o processo de branqueamento envolve múltiplas formas. Uma das situações que se faz presente é a do branqueamento físico que afeta, e muito, a percepção de que ser negra é ser feia. Por isso, há o alisamento dos cabelos pelas mulheres negras. Porém, há branqueamentos mais sensíveis, íntimos e severos: o branqueamento cultural, por exemplo, que é o processo de valorização da cultura branca em detrimento da cultura negra. Entre as formas de branqueamento cultural, o branqueamento linguístico é o que se torna essencial para qualquer processo de ascensão social do negro na sociedade racista. "Falar é estar em condições de empregar certa sintaxe, possuir a morfologia de tal ou qual língua, mas é sobretudo assumir uma cultura, suportar o peso de uma civilização"..$^{12}$ Oprimidos, os negros só serão tolerados na comunidade racista e poderão desfrutar de algumas pequenas sobras das mesas da elite (um trabalho, a ascensão a determinado grau de estudos, acesso a bens culturais) quando se tornarem assimilados. A representação do negro brasileiro enquanto ser se deu por parâmetros alheios à sua cultura, à sua vontade. Portanto, o povo negro existe enquanto objeto e não enquanto sujeito de fato e de direito.

A representação é o processo pelo qual membros de uma cultura usam a linguagem para instituir significados. Essa definição carrega uma premissa: as coisas, os objetos, os eventos do mundo não têm, neles mesmos, qualquer sentido fixo, final ou verdadeiro. Somos nós, em sociedade,

\footnotetext{
${ }^{10}$ FANON. Pele negra, máscaras brancas, p. 61, grifo meu.

${ }^{11}$ FANON. Pele negra, máscaras brancas, p. 34.

${ }^{12}$ FANON. Pele negra, máscaras brancas, p. 33.
} 
entre culturas humanas, que atribuímos sentidos às coisas. Os sentidos, consequentemente, sempre mudarão de uma cultura para outra e de uma época para outra. ${ }^{13}$

Quando analisamos as condições da mulher negra então, o caso é ainda mais grave. O preconceito contra a mulher negra se manifesta em pelo menos três dimensões: discriminação racial, discriminação de gênero e discriminação de classe social. Assim afirma Fanon: "Mesmo expondome ao ressentimento de meus irmãos de cor, direi que o negro não é um homem". ${ }^{14} \mathrm{E}$ é nele que busco inspiração para a escrita deste artigo. Contudo, e sinto muito em dizer que ainda que aborde especificamente em algumas páginas o caso da discriminação e do racismo e seus efeitos sobre a mulher negra, sobre sua autoestima, sobre sua percepção de estética física e artística, sobre o que é considerado belo ou não, o autor antilhano não aborda de forma direta e nem mesmo substancial o caso da mulher negra. Fanon não aborda como se dá o processo de solidão que sofre a mulher negra que é preterida pelos brancos ou usada apenas como objeto sexual fetichizado ou como é tratada pelos seus pares, homens negros como um ser que pouco ou nada poderá acrescentar em suas vidas - resquícios da ideia terrível de aprimoramento da raça.

Dentre os meios mais eficazes de destilação do ódio racista está o olhar. O olhar discriminatório surge como um sutil punhal em diversos momentos. Aquele olhar que desestrutura, que parece dizer: "este não é o seu lugar". Geralmente, este meio de aflorar o racismo ocorre em ambientes em que há pouca incidência de negros, em espaços sociais que têm sido tradicionalmente ocupados pela elite. Na citação que é apresentada a seguir, fica evidente que a discriminação pelo olhar ocorre em um contexto em que a negra não é bem-vinda:

[...] Elas me olhavam com uma indulgência insuportável. Sentia que estava com a maquiagem muito carregada, que não estava vestida como devia, que não estava à altura de André, talvez simplesmente por causa da minha pele; em resumo, passei uma noite tão desagradável que decidi nunca mais pedir a André para acompanhá-lo. ${ }^{15}$

\footnotetext{
${ }^{13}$ HALL. The Work of Representation, p. 61, tradução minha.

${ }^{14}$ FANON. Pele negra, máscaras brancas, p. 26.

${ }^{15}$ FANON. Pele negra, máscaras brancas, p.55.
} 
O olhar é uma das armas mais preconceituosas que existe. Contra esta arma não há nenhum artifício jurídico possível. O crime de racismo não é caracterizado pelos olhares. Contudo, é o olhar que é usado de forma preconceituosa quando um negro frequenta um espaço que é caracterizado como espaço de branco, como espaço da elite.

Depois que tivemos de enfrentar o olhar branco. Um peso inusitado nos oprimiu. O mundo verdadeiro invadia o nosso pedaço. No mundo branco, o homem de cor encontra dificuldades na elaboração de seu esquema corporal. $\mathrm{O}$ conhecimento do corpo é unicamente uma atividade de negação. É um conhecimento em terceira pessoa. ${ }^{16}$

O conhecimento de seu próprio corpo, o conhecimento de seu próprio existir não ocorre com suas percepções materiais, sensitivas, e sim por uma imposição do olhar do outro, do branco. "O negro, em determinados momentos, fica enclausurado no próprio corpo". ${ }^{17} \mathrm{Em}$ diversos momentos, o negro fica aprisionado em seu corpo, em um corpo desconhecido, em um corpo criado culturalmente pelo outro, pelo branco. Nem mesmo é possível para o negro resgatar resquícios de suas memórias antepassadas, pois estas estão soterradas pela historicidade escrita por mãos brancas. Afinal, quem tece nossas memórias?

Evaristo apresenta em Olhos d'água as memórias do povo negro, da mulher negra colocando-a em destaque e em posição protagonista. Ser o ator principal de suas próprias narrativas não é comum quando o negro é escrito. Há em Evaristo a memória do negro, a dor do negro e, ao mesmo tempo, o testemunho do crime do branco. Há na literatura dela uma crítica feroz aos brancos e à elite pelo lugar que relegaram aos negros na sociedade brasileira e o lirismo presente surge apenas para apresentar de forma ainda mais acentuada a dor da condição dos despejados, dos desterrados.

Às vezes, as histórias da infância de minha mãe confundiam-se com as de minha própria infância. Lembrome de que muitas vezes, quando a mãe cozinhava, da panela subia cheiro algum. Era como se cozinhasse, ali, apenas o nosso desesperado desejo de alimento.

${ }^{16}$ FANON. Pele negra, máscaras brancas, p.54.

${ }^{17}$ FANON. Pele negra, máscaras brancas, p.186. 
As labaredas, sob a água solitária que fervia na panela cheia de fome, pareciam debochar do vazio do nosso estômago, ignorando nossas bocas infantis em que as línguas brincavam a salivar sonho de comida. ${ }^{18}$

Ao observar o protagonismo da mulher negra, o conto de Evaristo já seria considerado um marco da literatura brasileira. Porém, não é apenas por isso, e sim por sua forma de explorar em sua narrativa elementos que funcionam ao mesmo tempo como crítica social para a elite e como ganchos de identidade para os negros. ${ }^{19} \mathrm{O}$ seu lirismo que reconstrói a força das mulheres negras e a manutenção da tradição pode ser encontrado no seguinte trecho do conto:

Hoje, quando já alcancei a cor dos olhos de minha mãe, tento descobrir a cor dos olhos de minha filha. Faço a brincadeira em que os olhos de uma se tornam o espelho para os olhos da outra. E um dia desses me surpreendi com um gesto de minha menina. Quando nós duas estávamos nesse doce jogo, ela tocou suavemente no meu rosto, me contemplando intensamente. E, enquanto jogava o olhar dela no meu, perguntou baixinho, mas tão baixinho, como se fosse uma pergunta para ela mesma, ou como estivesse buscando e encontrando a revelação de um mistério ou de um grande segredo. Eu escutei quando, sussurrando, minha filha falou: - Mãe, qual é a cor tão úmida de seus olhos? ${ }^{20}$

É na sensível brincadeira entre mãe e filha que se revela a dolorosa herança que se reflete em olhos úmidos. Olhos que carregam a memória de tempos de dificuldades. As mesmíssimas histórias se repetem, a fome é repassada entre gerações. Contudo, também nesta brincadeira que relembra feitos tristes, é retomada a esperança, a ancestralidade; a tradição cultural afro-brasileira renasce nos olhos d'água da mãe, que são refletidos nos da filha: "Minha mãe trazia, serenamente em si, águas

\footnotetext{
${ }^{18}$ EVARISTO. Olhos d'água, p.16.

${ }^{19}$ Os ganchos de identidade são instrumentos que ligam os negros a elementos próprios de sua ancestralidade. Em um país racista, a ancestralidade negra é constantemente bombardeada por posicionamentos preconceituosos que desvalorizam suas raízes. A literatura de Evaristo resgata e realoca esses elementos no local de prestígio em que deveriam estar.
}

${ }^{20}$ EVARISTO. Olhos d'água, p.19. 
correntezas. Por isso, prantos a enfeitar o seu rosto. A cor dos olhos de minha mãe era cor de olhos d'água. Águas de Mamãe Oxum!'”21 Nesta cena e em outras do conto, é perfeitamente identificado que permanece algo além da dor: a esperança e alguns rastros de tradição.

Às vezes, no final da tarde, antes que a noite tomasse conta do tempo, ela se assentava na soleira da porta e juntas ficávamos contemplando as artes das nuvens no céu. Umas viravam carneirinhos; outras, cachorrinhos; algumas, gigantes adormecidos, e havia aquelas que eram só nuvens, algodão doce. A mãe, então, espichava o braço que ia até o céu, colhia aquela nuvem, repartia em pedacinhos e enfiava rápido na boca de cada uma de nós. Tudo tinha de ser muito rápido, antes que a nuvem derretesse e com ela os nossos sonhos se esvaecessem também. Mas, de que cor eram os olhos de minha mãe?22

Neste momento é possível observar os estratagemas utilizados por Evaristo. Enquanto usa toda a ferocidade crítica de sua pena para apresentar a situação de miséria que é imposta à mulher negra, ela também emprega a mesma pena para buscar consolo e força para os que vivem em situação de subalternização. Na ludicidade, em meio à dor das dificuldades da vida, surge um momento terno entre mãe e filha. Evaristo revela o papel da poeticidade como instrumento de sobrevivência em situações difíceis.

E foi então que, tomada pelo desespero por não me lembrar de que cor seriam os olhos de minha mãe, naquele momento, resolvi deixar tudo e, no outro dia, voltar à cidade em que nasci. Eu precisava buscar o rosto de minha mãe, fixar o meu olhar no dela, para nunca mais esquecer a cor de seus olhos. E assim fiz. Voltei, aflita, mas satisfeita. Vivia a sensação de estar cumprindo um ritual, em que a oferenda aos Orixás deveria ser descoberta da cor dos olhos de minha mãe. ${ }^{23}$

${ }^{21}$ EVARISTO. Olhos d'água, p. 19.

${ }^{22}$ EVARISTO. Olhos d'água, p. 17.

${ }^{23}$ EVARISTO. Olhos d'água, p. 18. 
A busca de África é metaforicamente representada pela necessidade de retomar a lembrança dos olhos da mãe. O rosto materno representa os valores ancestrais perdidos na diáspora. A melhor oferenda aos Orixás é, portanto, a valorização da ancestralidade, a retomada das heranças perdidas, o passado mítico que fora deixado para trás após as voltas dadas ao redor da árvore do esquecimento. Analisando a trajetória autoral, o que se percebe em Evaristo é a transmutação do rito em escrita. O papel da palavra, portanto, nesta busca de oferendar o passado perdido, é crucial. A protagonista do conto vai buscar este poder da palavra em sua tradição ancestral em mulheres que "desde a África vinham arando a terra da vida com as suas próprias mãos, palavras e sangue". ${ }^{24}$ Domar os códigos linguísticos da elite, além de possibilitar ao negro ser o escritor de sua própria história, também funciona como estratégia para distorcer imagens estereotipadas e converter a língua de meio de dominação para instrumento de libertação.

[...] a palavra penetra literalmente em todas as relações entre indivíduos, nas relações de colaboração, nas de base ideológica, nos encontros fortuitos da vida cotidiana, nas relações de caráter político, etc. As palavras são tecidas a partir de uma multidão de fios ideológicos e servem de trama a todas as relações sociais em todos os domínios. É portanto claro que a palavra será sempre o indicador mais sensível de todas as transformações sociais, mesmo daquelas que apenas despontam, que ainda não tomaram forma, que ainda não abriram caminho para sistemas ideológicos estruturados e bem formados. ${ }^{25}$

Identidade e memória para a mulher negra na literatura de Evaristo são apresentadas como um processo de remendo, de recolher cacos, de bricoleur, de reconstrução a partir de quase nada, um quase nada que é quase tudo. A desconstrução, tão abordada pelos teóricos franceses, não funciona nos processos identitários do povo negro. Só há desconstrução quando houve algo sólido construído. A solidez da cultura negra é algo tão distante e que foi por inúmeras vezes dilapidada pelos saqueadores, pelos senhores de escravo e pelos patrões que já não é palpável em sua completude. Contudo, ainda resta a esperança que se reflete nas

${ }^{24}$ EVARISTO. Olhos d'água, p. 18, grifo meu.

${ }^{25}$ BAKHTIN. Marxismo e Filosofia da Linguagem, p. 41, grifo meu. 
personagens de Evaristo quando uma filha vê nos olhos da mãe a herança de uma tradição desestruturada pelas cotidianas violências sofridas. É preciso contar nossas histórias; e contar é também recriar, pois não há outro caminho. A Casa-grande se desequilibra quando o negro conta sua própria história, pois some qualquer heroísmo, qualquer mito de progresso quando ficam escancaradas as portas das antigas senzalas. Abrir a senzala é tornar público um crime que ainda insiste em ficar impune: "Minha negritude não é nem torre nem catedral / Ela mergulha na carne vermelha do solo / Ela mergulha na carne ardente do céu / Ela rasga a prostração opaca da paciência sensata..." 26 É preciso não ter medo de adentrar em searas sangrentas e ali buscar nossa identidade - ser negro é um processo complexo e, por vezes, doloroso.

Ser negro é, além disto, tomar consciência do processo ideológico que, através de um discurso mítico acerca de si, engendra uma estrutura de descobrimento que o aprisiona numa imagem alienada, na qual se reconhece. Ser negro é tomar posse desta consciência e criar uma nova consciência que reassegure o respeito às diferenças e que reafirme uma dignidade alheia a qualquer nível de exploração. Assim, ser negro não é uma condição dada, a priori, é um vir a ser. Ser negro é tornar-se negro. ${ }^{27}$

Quando aborda em seus livros a questão da violência, da fome, da discriminação, fica bem claro que Evaristo está construindo uma narrativa de testemunho. Em Olhos d'água quando mulheres de diferentes gerações observam nos olhos das outras as mesmas águas das lágrimas causadas pela opressão em que vivem fica evidente o círculo vicioso de exploração, dominação e violência. A exploração é relatada quando a protagonista relembra fatos de sua infância e dos poucos momentos de lazer de criança roubados pelo "lava-lava, o passa-passa das roupagens alheias [...]". ${ }^{28}$ Há na tradição dos oprimidos no Brasil a realidade escancarada do Estado de exceção: "A tradição dos oprimidos nos ensina que o 'estado de emergência' em que vivemos tornou-se a regra". ${ }^{29} \mathrm{~A}$ violência de cunho social caracteriza o Estado de exceção vivido pelo

\footnotetext{
${ }^{26}$ DIOP, Le Renégat, apud FANON. Pele negra, máscaras brancas, p. 124.

${ }^{27}$ SOUZA. Tornar-se negro, p. 77.

${ }^{28}$ EVARISTO. Olhos d'água, p. 16.

${ }^{29}$ BENJAMIN. Magia e técnica, arte e política, p. 697.
} 
negro no Brasil e abordado em conto de Evaristo por meio da fome e da miséria encaradas pelas personagens: "Lembro-me de que muitas vezes, quando a mãe cozinhava, da panela subia cheiro algum. Era como se cozinhasse, ali, apenas o nosso desesperado desejo de alimento". ${ }^{30}$ Há, portanto, nessa narrativa, algo além de protesto, há algo de notitia criminis, de denúncia pautada em fatos do cotidiano das grandes cidades.

A relação do cidadão que sofre o Estado de exceção com o direito é complexa. A princípio, há a necessidade de que se crie a ilusão do direito; isso é necessário para que o indivíduo cumpra os deveres e não busque de forma alguma a revolta: "[...] uma teoria do estado de exceção é, então, condição preliminar para se definir a relação que liga e, ao mesmo tempo, abandona o vivente ao direito". ${ }^{31}$ No Brasil, não existem leis que diferenciam, à priori, as pessoas. Porém, o direito também é constituído pelos costumes; é exatamente neste ponto que se verifica as mais variadas formas de distinções.

Creio que existe outro princípio de rarefação de um discurso que é, até certo ponto, complementar ao primeiro. Trata-se do autor. $\mathrm{O}$ autor, não entendido, é claro, como o indivíduo falante que pronunciou ou escreveu um texto, mas o autor como princípio de agrupamento do discurso, como unidade e origem de suas significações, como foco de sua coerência. ${ }^{32}$

Em Evaristo, urge uma autoria que reflita a condição social do negro. Por isso, ao abordar o posicionamento autoral, não me esqueço da autora empírica, uma mulher negra. Contudo, ao abordar a condição social do povo negro no Brasil, a autora, enquanto sujeito, é diluída no discurso literário alcançando assim a amplitude da voz autoral que se confunde com vozes que foram e que são constantemente silenciadas.

\footnotetext{
${ }^{30}$ EVARISTO. Olhos d'água, p. 16.

${ }^{31}$ AGAMBEN. Estado de exceção, p. 12.

${ }^{32}$ FOUCAULT. A ordem do discurso, p. 26.
} 


\section{Algumas considerações}

[...] Ao dizer, o sujeito significa em condições determinadas, impelido, de um lado, pela língua e, de outro, pelo mundo, pela sua experiência, por fatos que reclamam sentidos, e também por sua memória discursiva, por um saber/poder/ dever/dizer, em que os fatos fazem sentido por se inscreverem em formações discursivas que representam no discurso as injunções ideológicas. ${ }^{33}$

As considerações não podem ser finais. Agora mesmo, neste exato momento em que escrevo, um irmão ou irmã de cor é assassinada por um diabo sem nome, fruto do racismo que estrutura as relações sociais, econômicas e políticas do Brasil. Essa mesma situação se repete caleidoscopicamente em diversos países no mundo e de forma mais pungente naqueles que recolheram os meus antepassados como objetos e os escravizaram em distantes terras.

A literatura de Evaristo apresenta as dores do povo negro no Brasil. O Estado brasileiro se tornou uma máquina destrutiva que tenta de todas as formas consolidar o projeto de nação iniciado no século XVIII - o projeto de branqueamento do país: “[...] quando o estado de exceção em que eles se ligam e se indeterminam torna-se a regra, então o sistema jurídico-político transforma-se em uma máquina letal". ${ }^{34}$ A literatura funciona como estratégia de denúncia de violências sofridas no cotidiano:

E naquela noite a pergunta continuava me atormentando. Havia anos que eu estava fora de minha cidade natal. Saíra de minha casa em busca de melhor condição de vida para mim e para minha família: ela e minhas irmãs que tinham ficado para trás. Mas eu nunca esquecera a minha mãe. Reconhecia a importância dela na minha vida, não só dela, mas de minhas tias e todas as mulheres de minha família. [...] Não, eu não esqueço essas Senhoras, nossas Yabás, donas de tantas sabedorias. Mas de que cor eram os olhos de minha mãe? ${ }^{35}$

\footnotetext{
${ }^{33}$ ORLANDI. Discurso e leitura, p. 50-51

${ }^{34}$ AGAMBEN. Estado de exceção, p. 131.

${ }^{35}$ EVARISTO. Olhos d'água, p.18.
} 
Seria possível, então, recolher os cacos e partindo de escombros e rastros de um passado já fragmentado reconstruir a identidade do povo negro no Brasil? Talvez, a reconstrução não se dê de forma fácil ou completa; contudo, é possível e essencial que seja iniciada. A angústia da personagem do conto de Evaristo que busca recordar a cor dos olhos da mãe é metáfora também desse constante buscar da ancestralidade destruída pelas dores do passado e do presente. Porém, é uma obrigação buscar a cor dos olhos da mãe, da antiga mãe África.

Ainda assim, não retornaremos à África. A nossa África foi destruída por europeus no passado - porém, outra África segue viva dentro de nós; apesar de tudo, apesar de todos, apesar das inúmeras voltas na árvore do esquecimento. Ela é atemporal, a-histórica, pois a historicidade oficial não consegue saciar nossa fome de ancestralidade. Deste modo, a única imagem que reconhecemos é a de um território mítico. É preciso reconstruir uma África mãe. Consequentemente, repito para mim a prece de Fanon e percebo que assim ele viveu, e percebo que assim Conceição Evaristo vive, e percebo e peço que assim eu também viva: "Minha última prece: Ô meu corpo, faça sempre de mim um homem que questiona!"36 Assim seja!

\section{Referências}

AGAMBEN, Giorgio. Estado de exceção. Tradução de Iraci D. Poleti. 2. ed. São Paulo: Boitempo, 2011.

BAKHTIN, Mikhail. Marxismo e filosofia da linguagem. 9. ed. São Paulo: Hucitec, 1999.

BENJAMIN, Walter. Magia e técnica, arte e política: ensaios sobre a literatura e história da cultura. 6. ed. São Paulo: Brasiliense, 1993. (Obras Escolhidas, 1).

BAUMAN, Zygmunt. Identidade: entrevista a Benedetto Vecchi. Tradução de Carlos Alberto Medeiros. Rio de Janeiro: Jorge Zahar Ed., 2005.

BRECHT, Bertold. Poemas (1913-1956). São Paulo: Brasiliense, 1986. EVARISTO, Conceição. Olhos d'água. Rio de Janeiro: Pallas, 2017.

${ }^{36}$ FANON. Pele negra, máscaras brancas, p. 191. 
Aletria, Belo Horizonte, v. 29, n. 1, p. 179-195, 2019

FANON, Frantz. Pele negra, máscaras brancas. Salvador: EDUFBA, 2008.

FOUCAULT, Michel. A ordem do discurso. 12. ed. São Paulo: Loyola, 2005.

HALL, Stuart. The Work of Representation. In: Representation, Cultural Representations and Signifying Practices. London, New Delhi: Thousands Oaks, Sage, 1997.

SOUZA, Neusa Santos. Tornar-se negro. Rio de Janeiro: Graal, 1983.

ORLANDI, Eni Puccinelli. Discurso e leitura. 9. ed. São Paulo: Cortez, 2011.

Recebido em: 21 de outubro de 2018. Aprovado em: 26 de fevereiro de 2019. 